\title{
Silver, Gold, and Silver-Gold Bimetallic Nanoparticle-Decorated Dextran: Facile Synthesis and Versatile Tunability on the Antimicrobial Activity
}

\author{
Phan Nu Ha Diem, ${ }^{1}$ Ton Nu My Phuong $\mathbb{D}^{1},{ }^{1}$ Nguyen Quoc Hien $\mathbb{D}^{2},{ }^{2}$ Duong Tuan Quang $\left(\mathbb{D},{ }^{3}\right.$ \\ Tran Thai Hoa $\odot,{ }^{1}$ and Nguyen Duc Cuong $\oplus^{1,4}$ \\ ${ }^{1}$ University of Sciences, Hue University, 77 Nguyen Hue Street, Hue City, Vietnam \\ ${ }^{2}$ Research and Development Center for Radiation Technology, Vietnam Atomic Energy Institute, 202A, 11 Street, Linh Xuan Ward, \\ Thu Duc District, Ho Chi Minh City, Vietnam \\ ${ }^{3}$ University of Education, Hue University, 34 Le Loi Street, Hue City, Vietnam \\ ${ }^{4}$ School of Hospitality and Tourism, Hue University, 22 Lam Hoang Street, Hue City, Vietnam
}

Correspondence should be addressed to Tran Thai Hoa; thoa@hueuni.edu.vn

and Nguyen Duc Cuong; nguyenduccuong@hueuni.edu.vn

Received 2 July 2020; Revised 6 October 2020; Accepted 8 October 2020; Published 21 October 2020

Academic Editor: Ruibing Wang

Copyright (c) 2020 Phan Nu Ha Diem et al. This is an open access article distributed under the Creative Commons Attribution License, which permits unrestricted use, distribution, and reproduction in any medium, provided the original work is properly cited.

\begin{abstract}
The noble metal-based nanoparticles (NPs) have been considered as potential antimicrobial agents because of their good antibacterial and antifungal activities as well as biocompatible nature. In this study, we have introduced a simple and fast route to synthesize silver, gold, and silver-gold bimetallic NP-decorated dextran. The as-synthesized noble metal-based NPs with spherical geometry showed high dispersity in dextran. The antibacterial and antifungal of obtained nanomaterials were tested with Xanthomonas oryzae pv. oryzae (Xoo) bacteria and Magnaporthe grisea (M. grisea) fungi. The silver NPs and bimetallic NPs with high silver content in dextran exhibited excellent activity to inhibited the growth of the bacteria and fungi, whereas the gold/dextran has weak antimicrobial effects. The antibacterial and antifungal properties of silver-gold bimetallic NPs in dextran biopolymer can be tuned according to the content of silver in the bimetallic NPs. The obtained nanomaterials could open an entry to a new class of antibiotics.
\end{abstract}

\section{Introduction}

Nowadays, the antibiotic resistance is one of biggest threats to global health that encourages scientists to find new routes to develop more effective biocidal materials to overcome the challenges [1]. Nanoparticles (NPs) based on noble metals [2-6] have been emerged as a best alternative to antibacterial reagents due to their excellent antimicrobial activity and biocompatible nature that can be applied in biomedical implementations. Among them, $\mathrm{Au}, \mathrm{Ag}$, and bimetallic $\mathrm{Au}-\mathrm{Ag}$ NPs are of great interest because of their unique optoelectronic and antimicrobial properties [7]. Since ancient time, silver has been considered as an effective bactericide [8]. The nanostructures based on silver with abundant surface- active atoms showed effective antimicrobial activity to inhibit the growth of a broad spectrum of fungi and bacteria by destroying infectious microorganism [9-11]. Despite its wide application, several reports indicated that the Ag NPs exhibited cytotoxic effects on some mammalian cells $[4,12]$ and their therapeutic concentration window for the application as an antimicrobial agent should be extremely narrow [13]. The combination of Ag NPs with other noble metal could widely open their therapeutic window [12].

The Au NPs with localized surface plasmon resonance can convert to amount of heat during the process, which is useful in photothermal therapy applications such as targeting bacterial and cancer cells. The Au NPs were considered as less toxic metal and safe antibiotics [14]. However, the high 
cost and weak antibacterial activities are some disadvantages of the nanomaterials $[12,15]$. The promising strategy to improve the antibacterial activity of Au NPs and as well as reduce the toxicity of Ag NPs has been to design silver-gold bimetallic NPs. Silver-gold bimetallic NPs are attracting great attention for biomedical field because their antibacterial activity can be tuned by the composition or structure of the NPs, high stability in air, and biocompatibility [16]. Yang et al. [15] indicated that the Ag shell thickness of Au-Ag NPs influenced dramatically their antibacterial activity and biocompatibility. Ding et al. [17] reported that the Au-Ag NPs exhibited potent antibacterial effect as well as negligible toxicity to human dermal fibroblasts. Sapkota et al. [18] demonstrated that $\mathrm{SiO}_{2}-\mathrm{Au}-\mathrm{Ag}$ nanocomposites exhibited not only strong antibacterial activity against Gram-positive and Gramnegative bacteria but also good biocompatibility. Thus, a facile route, which can control easily the silver content in bimetallic NPs, is of huge potential for biomedical applications.

In general, the naked noble metal-based NPs are usually not stable in solution. Their surface is usually decorated by substrates such as graphene oxide [19], carbon [20], silica [21], carbon nitride [14], or capped by organic molecules in order to stabilize them [22]. Among various capping and stabilizing agents, the dextran plays a promising role for development of noble metal NP-based novelty materials because they are not only biodegradable, environmental benignity, highly abundant, and low-cost [23] but also has better biocompatibility, lower toxicity, and slower degradation in the human body in comparison with other polysaccharides [24]. Some previous reports indicated that noble metal NPs/dextran showed significant antitumor effects [25], effective activity against different fungal and bacterial strains [26].

Xanthomonas oryzae pv. oryzae (Xoo) and Magnaporthe grisea (M. grisea, also called Magnaporthe orylzae) are known as causal agents of leaf blight and paddy blast diseases, which are the most principal diseases of rice $[27,28]$. Inspired by the unique chemical, physical, and biological properties of nanoscale, some nanomaterials have been investigated to prevent bacterial light and blast fungus such as Ag NPs $[29,30]$, graphene oxide/silver NPs [31], copper NPs [32], $\mathrm{SiO}_{2}-\mathrm{Ag}$ nanocomposites [33], and $\mathrm{MgO}$ nanoflowers [34]. However, antimicrobial characteristics of $M$. grisea and Xoo of silver/dextran, gold/dextran, and particularly silver-gold bimetallic NP-decorated dextran are not investigated systematically.

Herein, we introduce the facile and fast strategy to synthesize Ag, Au, and Ag-Au bimetallic NP-decorated dextran that acts both reducing and capping agents. The antifungal and antibacterial effects of $\mathrm{Ag}, \mathrm{Au}$, and $\mathrm{Au}-\mathrm{Ag}$ bimetallic NP-decorated dextran against $M$. grisea and Xoo were tested for the first time.

\section{Experimental}

2.1. Synthesis of $A g, A u$, and $A g$-Au Bimetallic NP-Dextran Suspension. Dextran (molar mass 40000), silver sulfate $\left(\mathrm{Ag}_{2} \mathrm{SO}_{4}\right)$, and chloroauric acid $\left(\mathrm{HAuCl}_{4} 3 \mathrm{H}_{2} \mathrm{O}\right)$ were purchased from Sigma Aldrich and used without further purification. First, the aqueous solutions including $100 \mathrm{~mL}$ of $1 \mathrm{mM}\left[\mathrm{Ag}\left(\mathrm{NH}_{3}\right)_{2}\right]_{2} \mathrm{SO}_{4}, 100 \mathrm{~mL}$ of $1 \mathrm{mM} \mathrm{HAuCl}$, and
$100 \mathrm{~mL}$ of $5 \mathrm{wt} . \%$ dextran solution were previously prepared. For preparation of $100 \mathrm{~mL}$ of $1 \mathrm{mM}\left[\mathrm{Ag}\left(\mathrm{NH}_{3}\right)_{2}\right]_{2} \mathrm{SO}_{4}$ solution, $31.18 \mathrm{mg}$ of $\mathrm{Ag}_{2} \mathrm{SO}_{4}$ was completely dissolved in $5 \mathrm{~mL}$ of $\mathrm{NH}_{3}$ (5 $\left.\mathrm{wt} \%\right)$, and then a fixed volume of deionized water was added the mixture under magnetic stirring to obtain $100 \mathrm{~mL}$ aqueous solution of $1 \mathrm{mM}\left[\mathrm{Ag}\left(\mathrm{NH}_{3}\right)_{2}\right]_{2} \mathrm{SO}_{4}$. The solution of $1 \mathrm{mM} \mathrm{HAuCl}_{4}$ and $5 \mathrm{wt} . \%$ dextran was prepared by dissolving of $39.36 \mathrm{mg}$ of $\mathrm{HAuCl}_{4} 3 \mathrm{H}_{2} \mathrm{O}$ and $5 \mathrm{~g}$ of dextran in each Erlenmeyer flask containing $100 \mathrm{~mL}$ deionized water, respectively.

In a typical synthesis of Ag NPs-dextran, $10 \mathrm{~mL}$ of $1 \mathrm{mM}$ $\left[\mathrm{Ag}\left(\mathrm{NH}_{3}\right)_{2}\right]_{2} \mathrm{SO}_{4}$ solution was mixed with $7 \mathrm{~mL}$ of $\mathrm{NH}_{3}$ solution ( $\sim 5 \mathrm{wt} . \%)$ for $15 \mathrm{~min}$ to form a homogeneous solution, and then the mixture was aged at $90^{\circ} \mathrm{C}$ for 15 min under magnetic stirring. The estimated concentration of silver in the suspension was $63 \mu \mathrm{g} / \mathrm{mL}$. In a similar manner, the $\mathrm{Au}$ NPs-dextran was carried out by replacing the $10 \mathrm{~mL}$ of $1 \mathrm{mM}\left[\mathrm{Ag}\left(\mathrm{NH}_{3}\right)_{2}\right]_{2} \mathrm{SO}_{4}$ solution with $10 \mathrm{~mL}$ of $1 \mathrm{mM}$ $\mathrm{HAuCl}_{4}$ solution.

To synthesize Ag-Au bimetallic NPs-dextran, $10 \mathrm{~mL}$ mixtures containing $7 \mathrm{~mL}$ of $1 \mathrm{mM}\left[\mathrm{Ag}\left(\mathrm{NH}_{3}\right)_{2}\right]_{2} \mathrm{SO}_{4}$ and $3 \mathrm{~mL}$ of $1 \mathrm{mM} \mathrm{HAuCl}_{4}$ or $5 \mathrm{~mL}$ of $1 \mathrm{mM}\left[\mathrm{Ag}\left(\mathrm{NH}_{3}\right)_{2}\right]_{2} \mathrm{SO}_{4}$ and $5 \mathrm{~mL}$ of $1 \mathrm{mM} \mathrm{HAuCl}_{4}$ or $3 \mathrm{~mL}$ of $1 \mathrm{mM}\left[\mathrm{Ag}\left(\mathrm{NH}_{3}\right)_{2}\right]_{2} \mathrm{SO}_{4}$ and $7 \mathrm{~mL}$ of $1 \mathrm{mM} \mathrm{HAuCl}_{4}$ were previously prepared, and then the as-prepared mixtures were mixed with $7 \mathrm{~mL}$ of $\mathrm{NH}_{3}$ solution ( $\sim 5 \mathrm{wt} . \%)$ for $15 \mathrm{~min}$ to form a homogeneous solution. After that, the mixture was aged at $90^{\circ} \mathrm{C}$ for 15 min under magnetic stirring to obtain Ag-Au bimetallic NP-dextran suspension. With the $\left[\mathrm{Ag}\left(\mathrm{NH}_{3}\right)_{2}\right]_{2} \mathrm{SO}_{4}: \mathrm{HAuCl}_{4}$ molar ratio in the mixture that is $3: 7,5: 5$, and $7: 3$, the respective obtained product was named as samples S3, S5, and S7. The colloidal stability of samples is about $\sim 4$ weeks.

2.2. Material Characterization. X-ray diffraction patterns were recorded by a Bruker D8 Advance X-ray diffractometer. Scanning electron microscopy (SEM) and elemental analysis and energy dispersive X-ray spectroscopy (EDS) were analyzed by a JSM-5300LV instrument. Fourier transforminfrared spectroscopy (FTIR) spectrogram was measured using a Nicolet-6700 FTIR spectrometer, with a wavelength range of $4000-500 \mathrm{~cm}^{-1}$. Transmission electron microscopy (TEM) and high-resolution transmission electron microscopy (HRTEM) were performed using JEOL JEM 1230. The UV-vis spectra were obtained using a Jasco V-550 UV-vis spectrophotometer within the range of $350-700 \mathrm{~nm}$.

2.3. Antibacterial and Antifungal Tests. The inhibition of growth of microorganism of $\mathrm{Ag}, \mathrm{Au}$, and $\mathrm{Ag}$ - $\mathrm{Au}$ bimetallic NP-decorated dextran was carried out with bacterial Xoo and fungal $M$. grisea. For the antibacterial test, Modified Wakimoto's medium was previously prepared as the following: a mixture including $300 \mathrm{~g}$ of potato infusion, $5.0 \mathrm{~g}$ of peptone, $2 \mathrm{~g}$ of disodium phosphate $\left(\mathrm{Na}_{2} \mathrm{HPO}_{4}\right), 0.5 \mathrm{~g}$ of calcium nitrate $\left(\mathrm{Ca}\left(\mathrm{NO}_{3}\right)_{2}, 15 \mathrm{~g}\right.$ of sucrose, and $17 \mathrm{~g}$ of agar were mixed distilled water to form $1.0 \mathrm{~L}$ of suspension and then sterilized by autoclaving at $125^{\circ} \mathrm{C}$ for $15 \mathrm{~min}$. The obtained medium was used to cultivate the Xoo bacteria. The petri dishes each contained $10 \mathrm{~mL}$ of Wakimoto medium and $0.1 \mathrm{~mL}$ of each type of as-synthesized nanomaterial. For the 


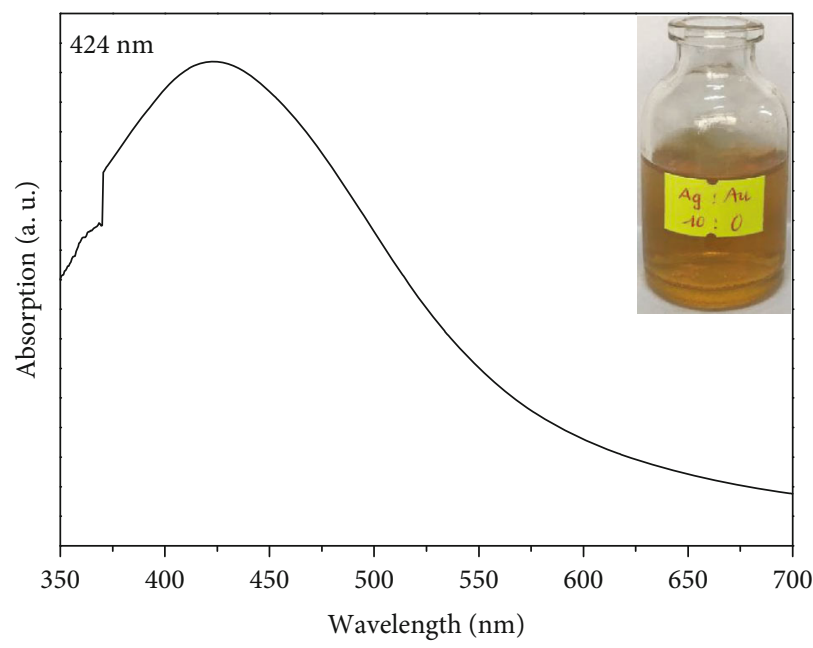

Wavelength $(\mathrm{nm})$
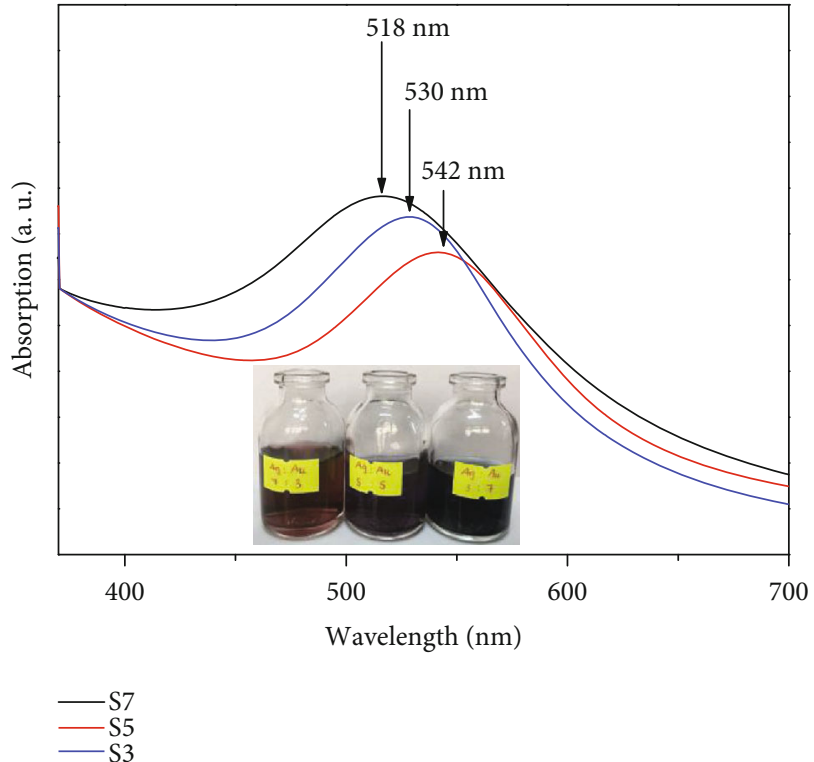

(a) (b)

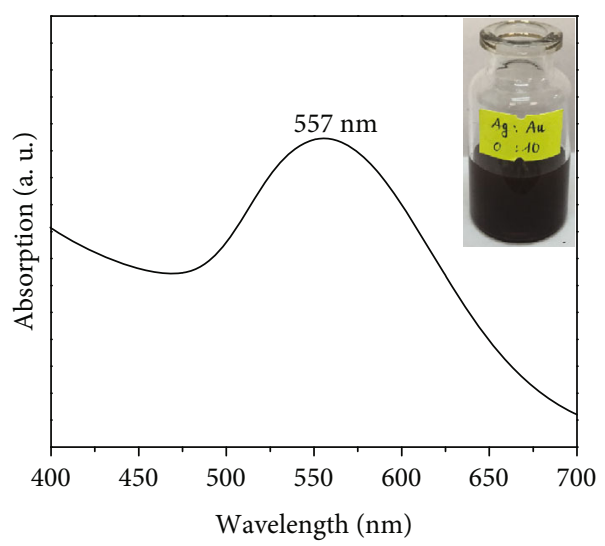

(c)

Figure 1: UV-visible absorption spectra of Ag NPs/dextran (a), silver-gold bimetallic NPs/dextran (b) and Au NPs/dextran (c), and respective colloidal suspension of these products.

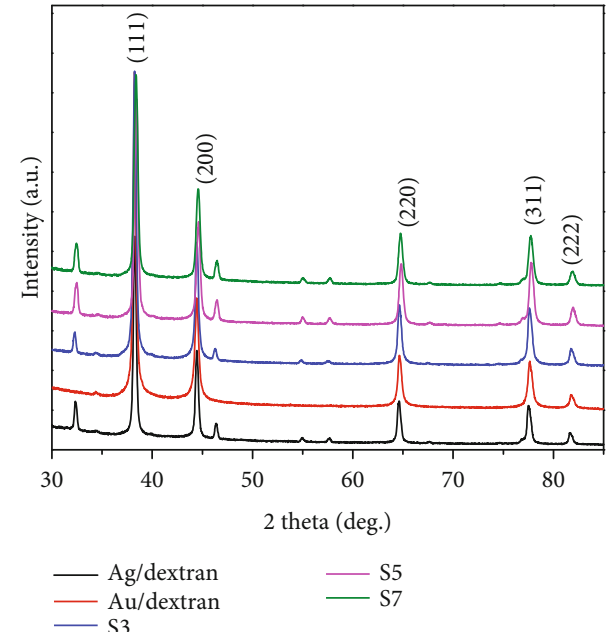

Figure 2: XRD pattern of $\mathrm{Ag}, \mathrm{Au}$, and $\mathrm{Ag}-\mathrm{Au}$ bimetallic NPdecorated dextran. nanomaterial as silver NPs/dextran, the estimated concentration of silver was used in the antibacterial test for about $6.3 \mu \mathrm{g} / \mathrm{mL}$. After that, $1 \mathrm{~mL}$ of bacterial Xoo suspension (approximately $10^{6} \mathrm{CFU} / \mathrm{ml}$ ) was spread onto these petri dishes followed by incubation of these plates at $28^{\circ} \mathrm{C}$ for $72 \mathrm{~h}$. One petri dish contained only $10 \mathrm{~mL}$ of Wakimoto medium but not containing the NPs has been made a similar process as a reference sample. Visible colonies were quantified after incubation.

The antifungal action of $\mathrm{Ag}, \mathrm{Au}$, and $\mathrm{Ag}-\mathrm{Au}$ bimetallic NP-

decorated dextran was evaluated against fungal $M$. grisea in potato dextrose agar (PDA) medium. To prepare PDA, a mixture composed of $200 \mathrm{~g}$ of potato infusion, $20 \mathrm{~g}$ of glucose, and $20 \mathrm{~g}$ of agar was dissolved and makes up to $1.0 \mathrm{~L}$ with distilled water and then sterilized into tubes lined autoclave at $125^{\circ} \mathrm{C}$ for $15 \mathrm{~min}$. The fresh PDA was taken in $10 \mathrm{~mL}$ for each petri dish and mixed with $0.1 \mathrm{~mL}$ of each type of assynthesized NPs. After that, $1 \mathrm{~mL}$ of fugal $M$. grisea strains (approximately $10^{6} \mathrm{CFU} / \mathrm{ml}$ ) was inoculated in these petri 


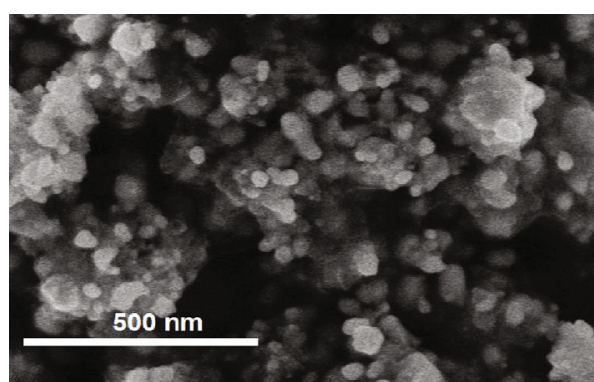

(a)

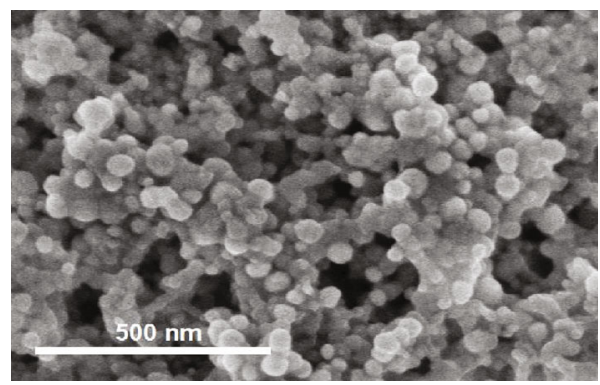

(c)

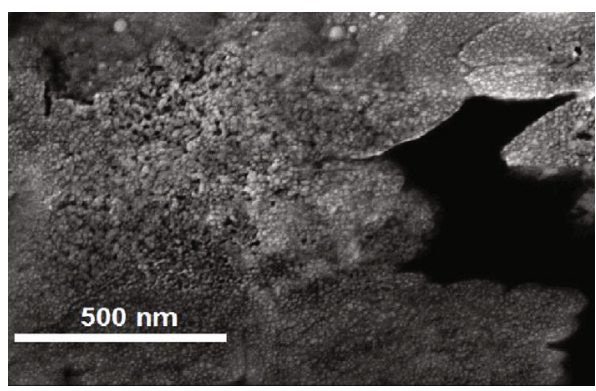

(e)

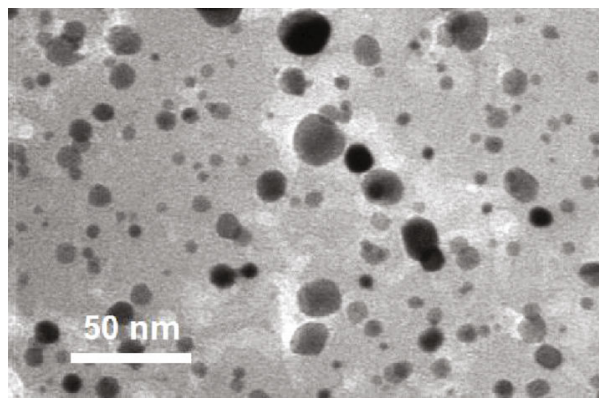

(g)

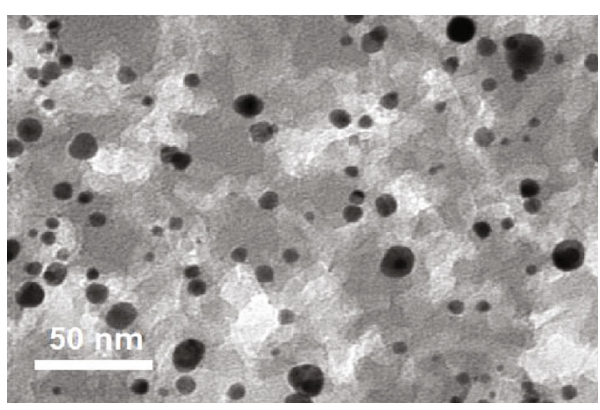

(i)

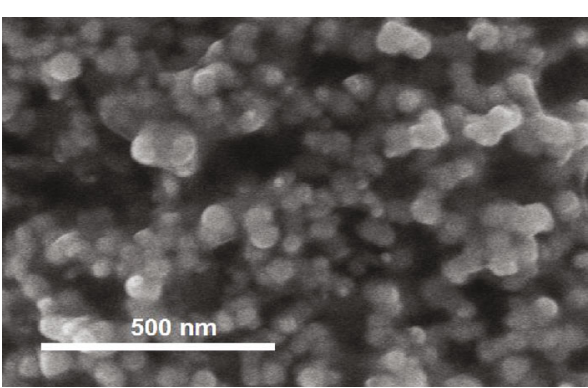

(b)

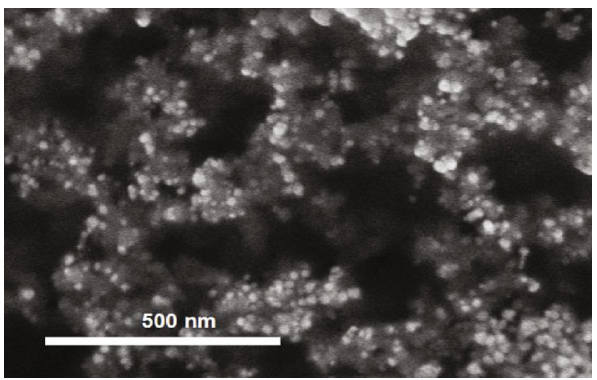

(d)

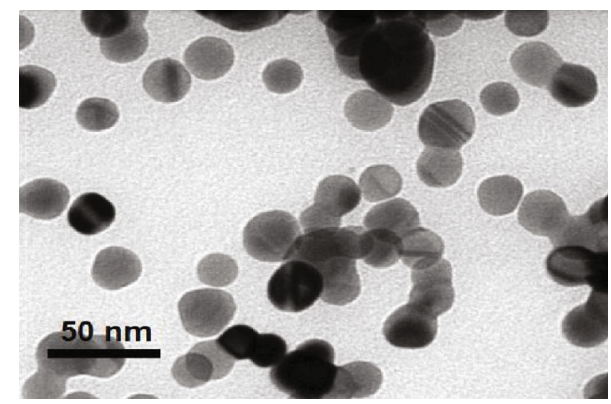

(f)

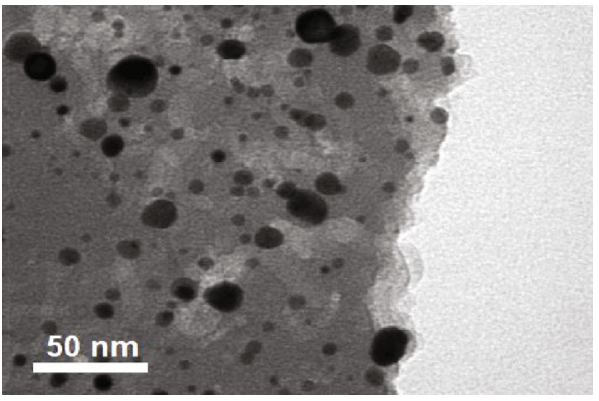

(h)

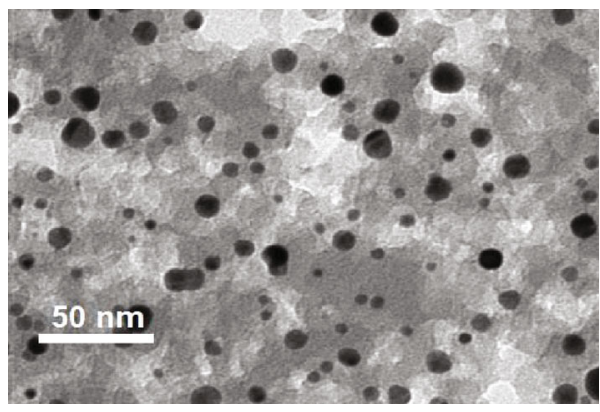

(j)

Figure 3: SEM and TEM images of Ag NPs/dextran (a, f), sample S7 (b, g), sample S5 (c, h), sample S3 (d, i), and Au NPs/dextran (e, j). 


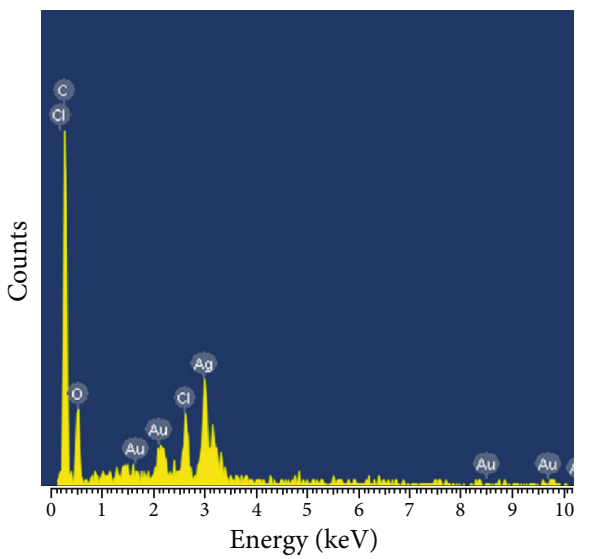

(a)

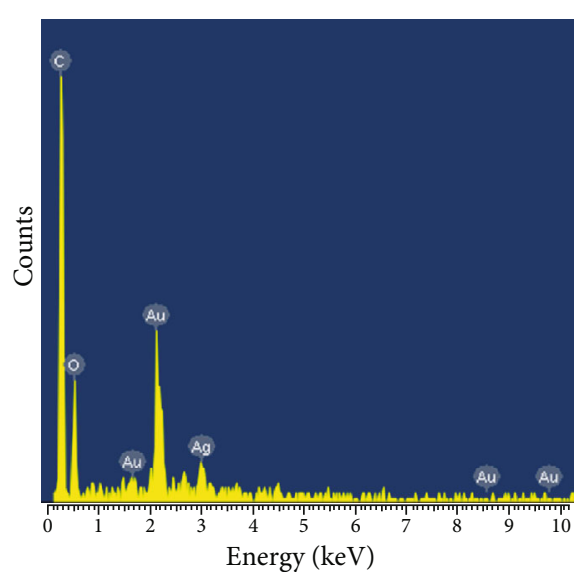

(c)

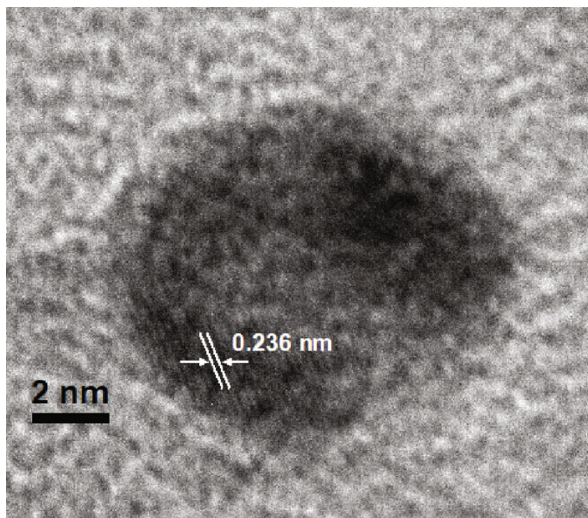

(e)

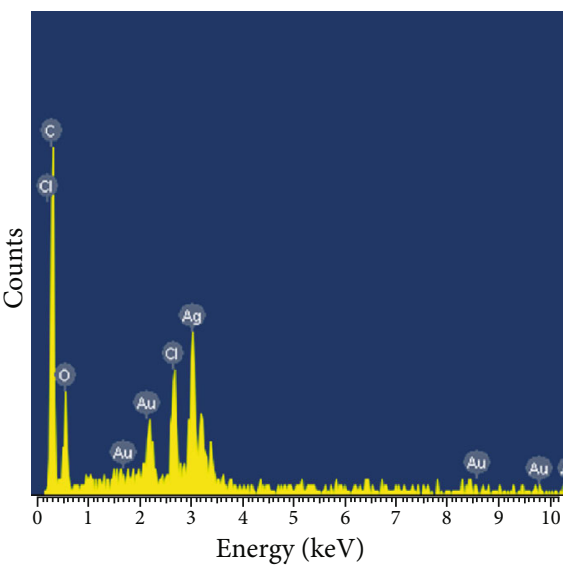

(b)

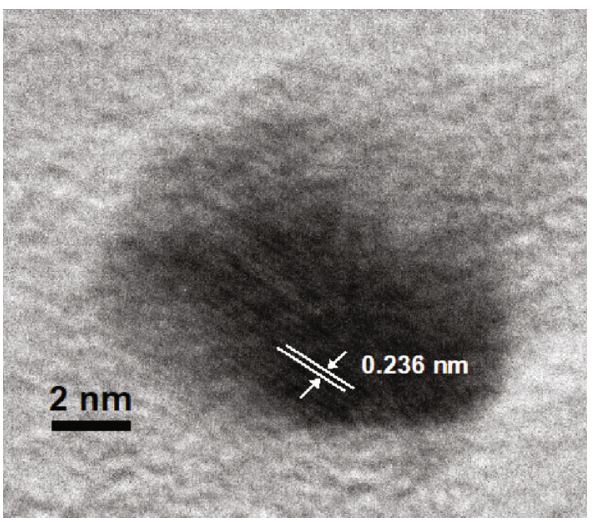

(d)

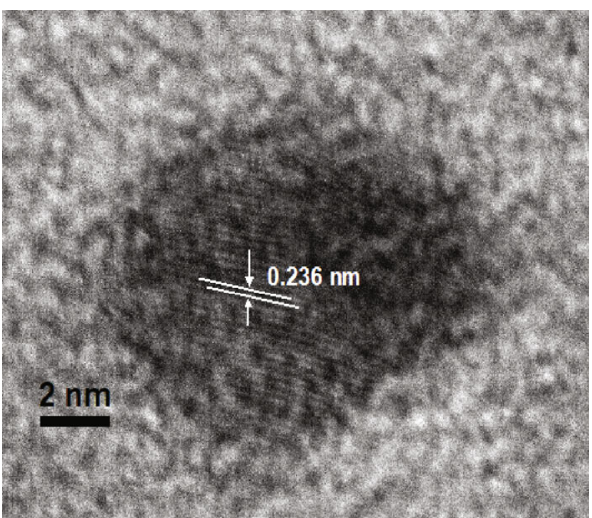

(f)

Figure 4: EDS analysis and HRTEM image of samples S7 (a, d), S5 (b, e), and S3 (c, f).

dishes. The inoculated plates were incubated at $28^{\circ} \mathrm{C}$ for 5 days. The size of fungus colonies was determined to calculate the inhibition efficiency of nanocomposites using the formula as suggested by Vincent [35].

Inhibition efficiency $(I, \%)=((C-T) / C) \times 100$,

in which $I, C$, and $T$ are the inhibition percentage, size of fungal colony in the reference sample, and the size of fungal colony in nanocomposite medium, respectively. Each test for the antimicrobial activity of these samples was repeated for three times to guarantee the uniformity.

\section{Results and Discussions}

The Ag, Au, and Ag-Au bimetallic NPs were synthesized by a fast and facile route in an aqueous phase with assistance of dextran. The dextran could act as a both reducing and stabilizing agent. The UV-visible absorptions of obtained silver, gold, and silver-gold bimetallic NPs in dextran were shown in Figure 1. As can be seen in Figures 1(a) and 1(c), the UV-visible spectra of the silver/dextran and gold/dextran exhibited bands at $424 \mathrm{~nm}$ and $557 \mathrm{~nm}$, respectively, which 
could be indexed to the visible surface plasmon resonance band of respective Ag and Au NPs [36, 37]. Compared with the spectroscopic profile of $\mathrm{Ag} / \mathrm{dextran}$ and $\mathrm{Au} /$ dextran colloid suspensions, the UV-visible absorption bands of $\mathrm{Ag}-\mathrm{Au}$ bimetallic NPs in dextran were 518, 530, and $542 \mathrm{~nm}$ for samples S7, S5, and S3, respectively, suggesting that a longer surface plasmon resonance wavelength could be tuned through decreasing the raw ratio of $\mathrm{Ag} / \mathrm{Au}$. The presence of only a single surface plasmon resonance band in these samples could originate to the formation of bimetallic Au-Ag NPs instead of a mixture of monometallic NPs $[38,39]$. The respective solutions of silver, silver-gold bimetallic, and gold NP colloidal suspension were shown inset in Figures 1(a)-1(c), respectively, as can be observed that their colors ranged from pale yellow ( $\mathrm{Ag} / \mathrm{dextran})$ to dark red ( $\mathrm{Au} /$ dextran) with intermediate hues for bimetallic samples.

The XRD patterns of the of silver and gold NPs in dextran in Figure 2 presented the typical diffraction peaks at $38.2^{\circ}, 44.4^{\circ}, 64.7^{\circ}, 77.7^{\circ}$, and $81.8^{\circ}$ corresponded to (111), (200), (220), (311), and (222) planes of face-centered cubic silver (JCPDS card no. 89-3722) and gold (JCPDS card no. $04-0784)$. Because the silver $(0.409 \mathrm{~nm})$ and gold $(0.408 \mathrm{~nm})$ are very similar lattice parameters, their XRD patterns almost overlap [40]. Several peaks related to crystal planes of $\mathrm{AgCl}$ were observed at $32.4^{\circ}, 46.4^{\circ}, 54.6^{\circ}$, and $57.7^{\circ}$ (JCPDS card no. 031-1238) in XRD patterns of silver/dextran and silvergold bimetallic samples. The coexistence of $\mathrm{AgCl}$ in the synthetic process of $\mathrm{Ag}$ NPs is a common observance reported in literature [41, 42]. The XRD patterns of silver-gold bimetallic NPs in dextran are very similar to those of the silver and gold NPs samples, which can be explained that the bimetallic samples have a similar crystal lattice structure with pristine silver and gold [43].

The morphology and particle size of silver, gold, and silver-gold bimetallic NP-decorated dextran were analyzed by SEM and TEM techniques. The SEM images (Figures 3(a)-3(e) and low magnification of TEM images (Figure S1) indicated that the obtained silver, gold, and silver-gold bimetallic NPs in dextran are high dispersity. The higher magnification of TEM images (Figures 3(f)-3(j) of samples showed that most of NPs were spherical geometry. The particle size of silver NPs in dextran ranges from 5 to $55 \mathrm{~nm}$ with the average particle size of $\sim 17.5 \mathrm{~nm}$ (Figure S2 (a)). In contrast to the result of Ag/dextran, the particle size of Ag-Au bimetallic NPs in dextran decreases significantly (Figures 3(c)-3(h). The average diameter of Ag-Au bimetallic NPs is $\sim 5 \mathrm{~nm}$ (Figure S2 (b-d)), which is similar to that of Au NPs in dextran (Figure S2 (e)). As can be seen in TEM image in Figure S1 (b), the sample with the highest atomic percentages of $\mathrm{Ag}$ in the bimetallic NPs (S7), many NPs with a diameter range of 20 to $40 \mathrm{~nm}$, was observed clearly. These particles were also observed in sample S5; however, they decreased in comparison with that of sample S7 (Figure S1 (b) and (c) and Figure S2 (b) and (c)). The particle size of bimetallic NPs fabricated with the highest atomic percentages of gold (S3) range from 3 to $25 \mathrm{~nm}$ that have better narrow particle size distribution than that of samples S7 and S5. Furthermore, particle size distribution analysis of sample S3 concurs with the results

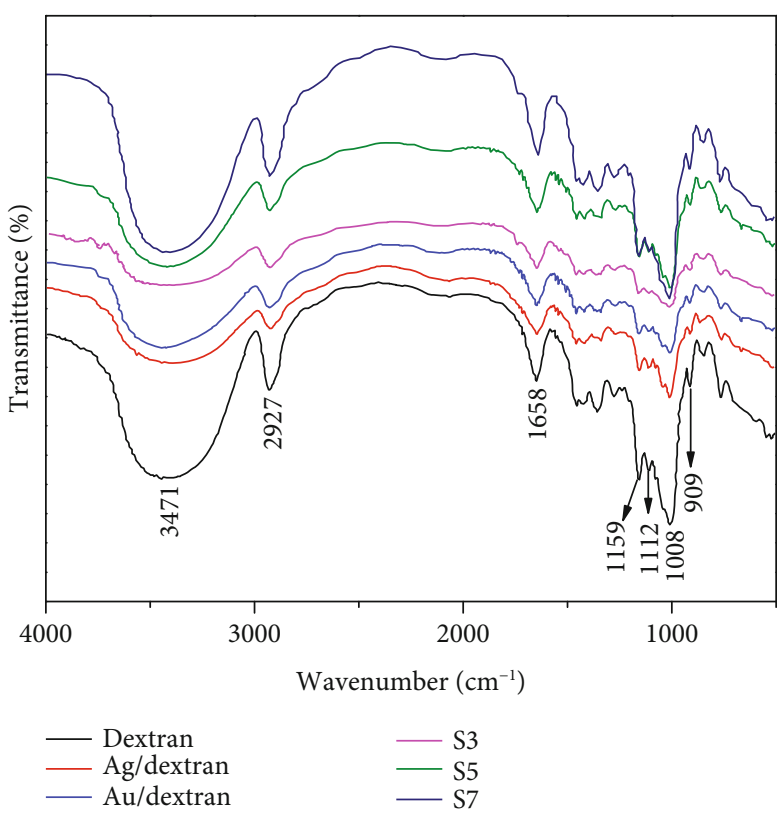

Figure 5: FTIR spectra of Ag, $\mathrm{Au}$, and $\mathrm{Ag}$-Au bimetallic NPs in dextran.

of Au/dextran. Our findings may be explained by the higher reactivity of silver compounds; thus, the preparation of silver NPs with well-controlled dimension was more difficult than that of gold NPs [44].

The chemical composition of bimetallic products was carried out by EDS (a)-(c) attached to the SEM that was presented in Figure 4. The results indicated distinctly the main peak of $\mathrm{Ag}-\mathrm{Au}$ bimetallic/dextran nanocomposite that can be assigned to $\mathrm{Ag}, \mathrm{Au}, \mathrm{O}$, and $\mathrm{C}$. After the synthetic process, the atomic ratio of $\mathrm{Ag} / \mathrm{Au}$ in the bimetallic NPs changes slightly in comparison with the nominal composition (Table S1 and Table S2 and Table S3). The HRTEM images and the bimetallic NP samples (S7, S5, and S3) did not show either dark area or lighter area, demonstrating that the bimetallic NPs are alloy formulation.

FTIR spectrum of pure dextran and NP-decorated dextran samples was presented in Figure 5. From the FTIR spectrum of dextran, the major peaks of dextran were observed clearly at $3471 \mathrm{~cm}^{-1}, 2927 \mathrm{~cm}^{-1}, 1658 \mathrm{~cm}^{-1}, \quad 1159 \mathrm{~cm}^{-1}$, $1112 \mathrm{~cm}^{-1}, 1008 \mathrm{~cm}^{-1}$, and $909 \mathrm{~cm}^{-1}$. Therein, the region of $3471 \mathrm{~cm}^{-1}$ was assigned to the stretching vibration of hydroxyl groups [45]. The peaks at $2927 \mathrm{~cm}^{-1}$ and $1658 \mathrm{~cm}^{-1}$ were attributed to the $\mathrm{C}-\mathrm{H}$ bond and carboxyl groups, respectively. The bands at $1159 \mathrm{~cm}^{-1}$ and $1112 \mathrm{~cm}^{-1}$ were due to stretching vibrations of the $\mathrm{C}-\mathrm{O}-\mathrm{C}$ bond and $\mathrm{C}-\mathrm{O}$ bond at the $\mathrm{C}-4$ position of glucose, respectively [46]. The presence of peak at $909 \mathrm{~cm}^{-1}$ related to the existence of $\alpha$-glycosidic bond, and the absorption peak at $1008 \mathrm{~cm}^{-1}$ was due to the great chain flexibility around the $\alpha(1 \rightarrow 6)$ glycosidic bonds [46]. The FTIR spectra of silver, gold, and bimetallic NP-decorated dextran exhibited a similarity with that of dextran. However, there was a light shifting of bands assigning to the hydroxyl and carbonyl functional groups (Table S4), indicating that the surface of silver, gold, and silver-gold bimetallic NPs was adsorbed by these groups [47, 48]. 


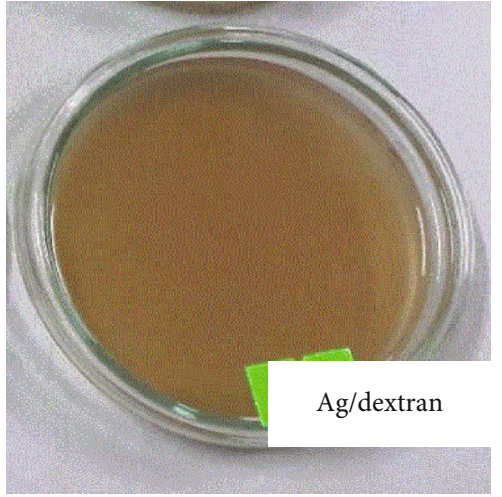

(a)

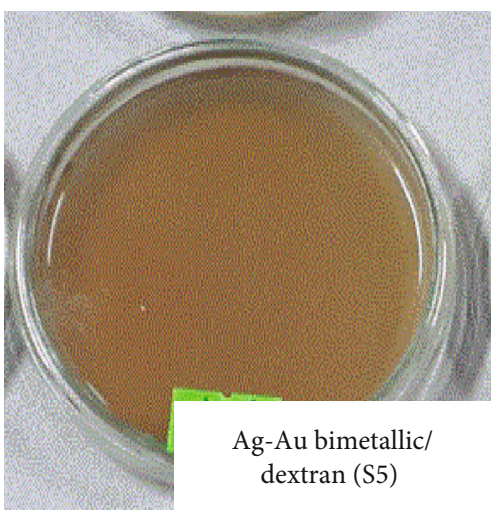

(c)

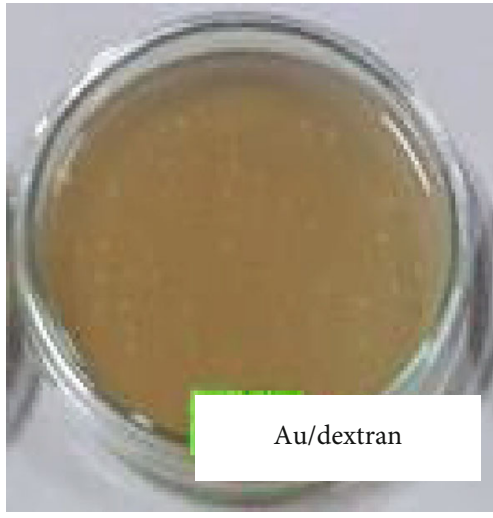

(e)

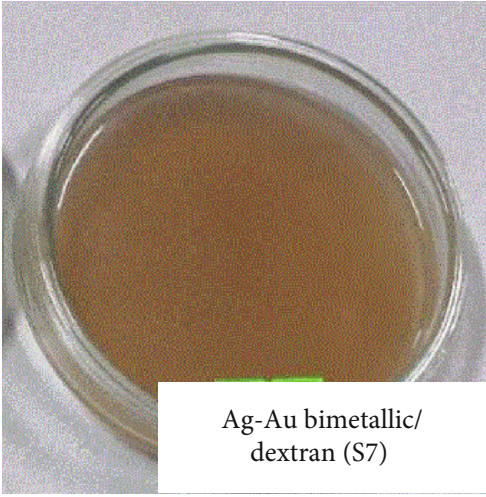

(b)

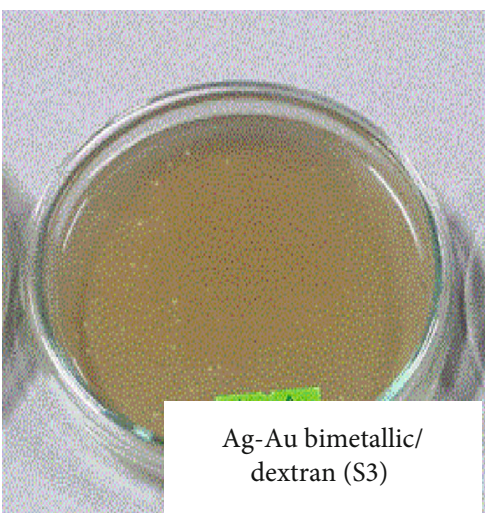

(d)

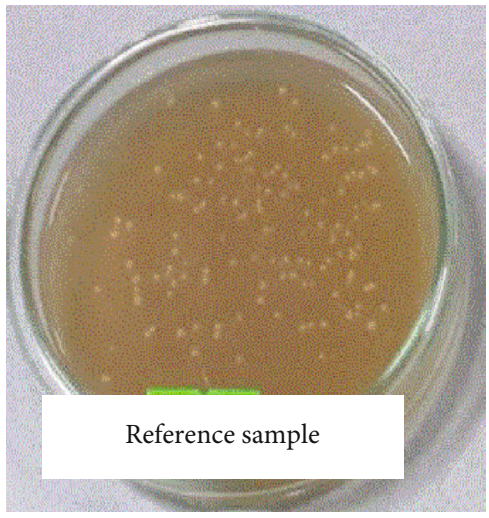

(f)

FIgURE 6: The optical images of Xoo colonies incubated on silver NPs/dextran (a), sample S7 (b), sample S5 (c), sample S3 (d), gold NPs/dextran (e), and the blank control sample (f).

The antibacterial property of the as-prepared silver, gold, and silver-gold bimetallic NP-decorated dextran was tested against bacterial Xoo strains. The optical images of Xoo colonies incubated on the blank control sample and $\mathrm{NP} /$ dextran samples for $72 \mathrm{~h}$ were shown in Figure 6. It is clearly observed that there are almost no colonies in Figures 6(a)-6(c), revealing that the silver NPs/dextran and samples S7 and S5 are effective inhibition the growth of Xoo. The colonies appeared clearly in the petri dish containing sample S3 (the bimetallic NPs with the lowest content of silver), whereas the gold NP-decorated dextran exhibited a weakly inhibited growth of Xoo. These results indicated that the antibacterial activity of bimetallic sam- ples could relate to the silver content in the NPs, which could originate the excellent and broad-spectrum antimicrobial activity of silver [49]. The decrease of the silver content in the bimetallic NPs is without significantly reducing their antibacterial properties, which could be useful for biomedical applications.

The antifungal properties of $\mathrm{Ag}, \mathrm{Au}$, and $\mathrm{Ag}$ - $\mathrm{Au}$ bimetallic NPs in dextran were tested with M. grisea by determining the size of the fungal colonies that was measured after 5 days. The optical images of colonies of the fungal growth in media with and without nanocomposite sample are shown in Figure 7 . The results indicated that the silver NP-decorated dextran inhibited significantly the development of $M$. grisea 


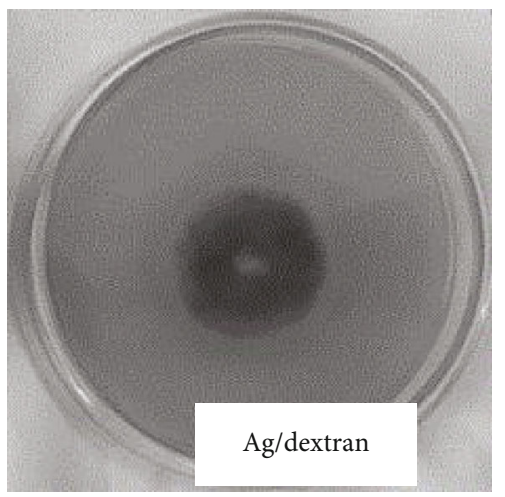

(a)

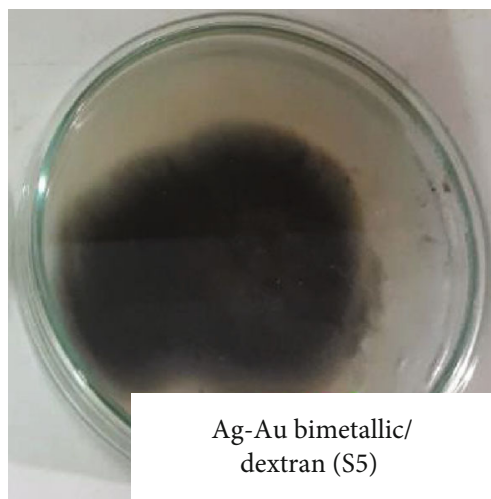

(c)

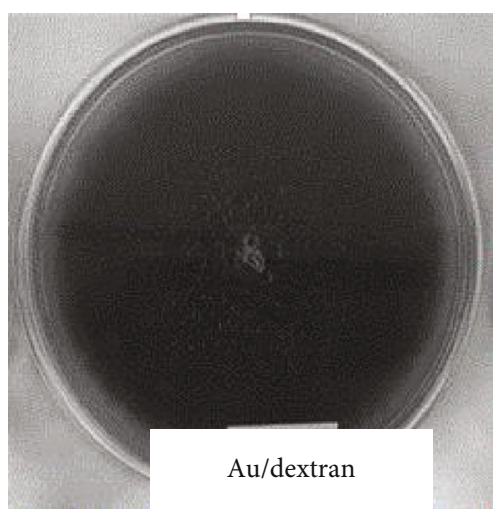

(e)

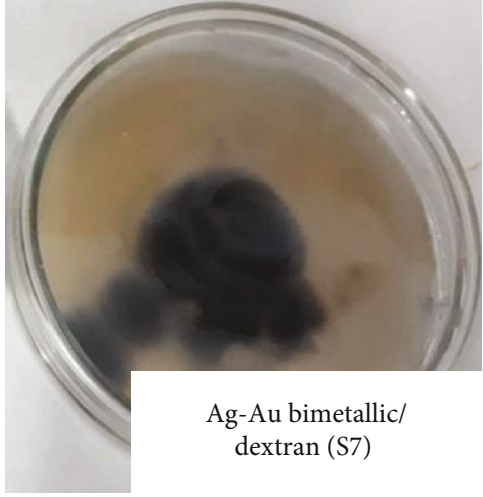

(b)

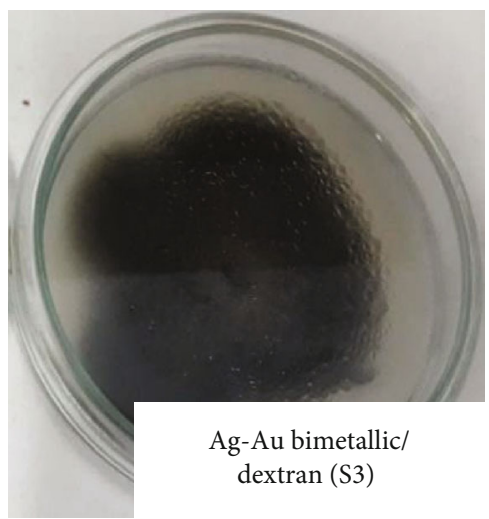

(d)

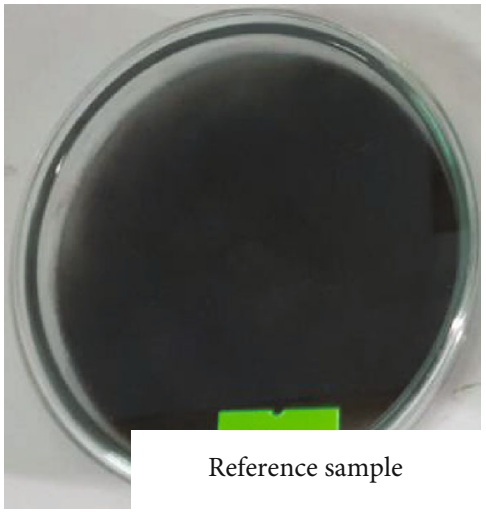

(f)

Figure 7: The optical images of M. grisea colonies incubated on silver NPs/dextran (a), sample S7 (b), sample S5 (c), sample S3 (d), gold NPs/dextran (e), and the blank control sample (f).

TABle 1: The diameter of fungal colonies and respective fungal inhibition efficiency of nanocomposites.

\begin{tabular}{lcc}
\hline Sample & Diameter of colony $(\mathrm{cm})$ & Efficiency $(\%)$ \\
\hline Reference & $3.60 \pm 0.08$ & 0 \\
Gold/dextran & $3.43 \pm 0.10$ & 4.72 \\
S3 & $2.93 \pm 0.11$ & 18.61 \\
S5 & $2.48 \pm 0.09$ & 31.11 \\
S7 & $2.21 \pm 0.08$ & 38.61 \\
Silver/dextran & $1.09 \pm 0.12$ & 69.72 \\
\hline
\end{tabular}

(its inhibition efficiency of $69.72 \%$ ). Similar to the antibacterial properties, the $M$. grisea antifungal characteristic of silver-gold bimetallic NPs/dextran decreased with the decrease of the silver content in the bimetallic NPs. The inhibition efficiencies of bimetallic NPs were $38.6 \%, 31.1 \%$, and $18.6 \%$ for samples S7, S5, and S3, respectively (Table 1), whereas the inhibition efficiency of gold/dextran was only $4.72 \%$ that indicated that the gold/dextran has a weak effect against $M$. grisea (Table 1 ). The results suggest that the Ag/dextran and bimetallic samples with high silver content (S7, S5) showed good antimicrobial activity against Xoo bacteria and $M$. grisea fungi, whereas the gold/dextran 
showed a weak effect to inhibit the growth of Xoo bacteria and $M$. grisea fungi. The formation of silver-gold bimetallic NPs in dextran may reduce significantly the concentration of silver. The concentration of silver of samples S7 and S5 were used in each microbial test that was estimated about 4.4 and $3.1 \mu \mathrm{g} / \mathrm{mL}$, respectively. The versatile tunability on the antimicrobial activity of Ag-Au alloy NPs may relate to the change in amount of silver atoms on the particle surface by controlling the different proportions of the $\left[\mathrm{Ag}\left(\mathrm{NH}_{3}\right)_{2}\right]_{2} \mathrm{SO}_{4}: \mathrm{HAuCl}_{4}$ molar ratio. The formation of silver-gold bimetallic NPs was known to decrease Ag dissolution behavior that reduce the overall toxicity of silver-based NPs [50]. Furthermore, the NPs were capped dextran that was biocompatibility polymer and antimicrobial activity [51]. Thus, these obtained materials could be investigated further to apply in nanomedicine.

\section{Conclusions}

In summary, the monodispersed silver, gold, and silver-gold bimetallic NPs in dextran were synthesized by a simple and fast process. The silver/dextran showed excellent antimicrobial properties against Xoo and M. gresia. The silver-gold bimetallic NPs exhibited remarkably and enhanced the inhibition of the growth of these microorganisms compared to the gold/dextran, and these samples showed a versatile tunability on the antimicrobial activity. Thus, we believe that the as-prepared nanocomposites could be considered as promising candidates for antiseptic and pharmaceutical fields.

\section{Data Availability}

The data used to support the findings of this study are included within the article and the supplementary information file.

\section{Conflicts of Interest}

The author(s) declare(s) that there is no conflict of interest regarding the publication of this manuscript.

\section{Acknowledgments}

This research was funded by the Ministry of Education and Training for The Development of Science and Technology, with a code of B2019-DHH-562-06.

\section{Supplementary Materials}

The supplementary materials have two figures and four tables that include the following: Figure S1 showed low magnification TEM images of Ag/dextran, sample S7, sample S5, sample S3, and Au/dextran to clearly observe the morphology and size of obtained nanocomposites. Figure S2 exhibited particle size distribution analysis of Ag/dextran, Au/dextran, and Ag-Au bimetallic nanoparticles in dextran to clearly analyze the diameter of as-synthesized nanoparticles. Tables S1-S3 exhibited elemental composition of samples S7, S5, and S3 to clearly demonstrate the chemical compo- sition of alloy nanoparticles. Table S4 showed the bands of hydroxyl and carbonyl stretching vibration of dextran, Ag/dextran, Au/dextran, and Ag-Au bimetallic/dextran to confirm the light shifting of bands assigning to the hydroxyl and carbonyl functional groups indicating the formation of silver, gold and silver-gold bimetallic nanoparticles. (Supplementary Materials)

\section{References}

[1] G. V. Vimbela, S. M. Ngo, C. Fraze, L. Yang, and D. A. Stout, "Antibacterial properties and toxicity from metallic nanomaterials," International Journal of Nanomedicine, vol. 12, pp. 3941-3965, 2017.

[2] J. S. Kim, E. Kuk, K. N. Yu et al., "Antimicrobial effects of silver nanoparticles, Nanomedicine nanotechnology," Biologie et Médecine, vol. 3, pp. 95-101, 2007.

[3] M. M. Mohamed, S. A. Fouad, H. A. Elshoky, G. M. Mohammed, and T. A. Salaheldin, "Antibacterial effect of gold nanoparticles against Corynebacterium pseudotuberculosis," International Journal of Veterinary Science and Medicine, vol. 5, pp. 23-29, 2019.

[4] N. Yadav, A. K. Jaiswal, K. K. Dey et al., “Trimetallic au/Pt/Ag based nanofluid for enhanced antibacterial response," Materials Chemistry and Physics, vol. 218, pp. 10-17, 2018.

[5] P. Boomi, H. G. Prabu, and J. Mathiyarasu, "Synthesis, characterization and antibacterial activity of polyaniline/Pt-Pd nanocomposite," European Journal of Medicinal Chemistry, vol. 72, pp. 18-25, 2014.

[6] P. M. Anjana, M. R. Bindhu, M. Umadevi, and R. B. Rakhi, "Antibacterial and electrochemical activities of silver, gold, and palladium nanoparticles dispersed amorphous carbon composites," Applied Surface Science, vol. 479, pp. 96-104, 2019.

[7] Z. Zhang and P. C. Lin, Noble Metal Nanoparticles: Synthesis, and Biomedical Implementations, Elsevier Inc., 2018.

[8] G. Franci, A. Falanga, S. Galdiero et al., "Silver nanoparticles as potential antibacterial agents," Molecules, vol. 20, no. 5, pp. 8856-8874, 2015.

[9] X. Zhang, H. Sun, S. Tan, J. Gao, Y. Fu, and Z. Liu, "Hydrothermal synthesis of $\mathrm{Ag}$ nanoparticles on the nanocellulose and their antibacterial study," Inorganic Chemistry Communications, vol. 100, pp. 44-50, 2019.

[10] Y. Wang, Y. Wang, L. Su, Y. Luan, X. Du, and X. Zhang, "Effect of surface topology morphologies of silica nanocarriers on the loading of Ag nanoparticles and antibacterial performance," Journal of Alloys and Compounds, vol. 783, pp. 136-144, 2019.

[11] N. T. Nguyen, D. L. Tran, D. C. Nguyen et al., "Facile synthesis of multifunctional $\mathrm{Ag} / \mathrm{Fe}_{3} \mathrm{O}_{4}$-CS nanocomposites for antibacterial and hyperthermic applications," Current Applied Physics, vol. 15, no. 11, pp. 1482-1487, 2015.

[12] Y. Wang, J. Wan, R. J. Miron, Y. Zhao, and Y. Zhang, “Antibacterial properties and mechanisms of gold-silver nanocages," Nanoscale, vol. 8, no. 21, pp. 11143-11152, 2016.

[13] L. Pauksch, S. Hartmann, M. Rohnke et al., "Biocompatibility of silver nanoparticles and silver ions in primary human mesenchymal stem cells and osteoblasts," Acta Biomaterialia, vol. 10, no. 1, pp. 439-449, 2014.

[14] Y. Chang, Z. Liu, X. Shen et al., "Synthesis of au nanoparticledecorated carbon nitride nanorods with plasmon-enhanced photoabsorption and photocatalytic activity for removing 
various pollutants from water," Journal of Hazardous Materials, vol. 344, pp. 1188-1197, 2018.

[15] L. Yang, W. Yan, H. Wang, H. Zhuang, and J. Zhang, "Shell thickness-dependent antibacterial activity and biocompatibility of gold@silver core-shell nanoparticles," RSC Advances, vol. 7, no. 19, pp. 11355-11361, 2017.

[16] W. Liao, Q. Lin, Y. Xu, E. Yang, and Y. Duan, "Preparation of au@Ag core-shell nanoparticle decorated silicon nanowires for bacterial capture and sensing combined with laser induced breakdown spectroscopy and surface-enhanced Raman spectroscopy," Nanoscale, vol. 11, no. 12, pp. 5346-5354, 2019.

[17] X. Ding, P. Yuan, N. Gao, H. Zhu, Y. Y. Yang, and Q. H. Xu, "Au-Ag core-shell nanoparticles for simultaneous bacterial imaging and synergistic antibacterial activity, Nanomedicine nanotechnology," Biologie et Médecine, vol. 13, pp. 297-305, 2017.

[18] K. Sapkota, P. Chaudhary, and S. S. Han, "Environmentally sustainable route to $\mathrm{SiO}_{2} @ a u-\mathrm{Ag}$ nanocomposites for biomedical and catalytic applications," RSC Advances, vol. 8, no. 55, pp. 31311-31321, 2018.

[19] F. Kordi, A. Khorsand Zak, M. Darroudi, and M. Hazrati Saedabadi, "Synthesis and characterizations of Ag-decorated graphene oxide nanosheets and their cytotoxicity studies," Chemical Papers, vol. 73, no. 8, pp. 1945-1952, 2019.

[20] S. Cheng, S. Zhan, X. Wu et al., "Insulating plasmonic photothermal heat of Ag nanoparticles by a thin carbon shell," Journal of Alloys and Compounds, vol. 791, pp. 380-384, 2019.

[21] H. Lee, S. Han, and Y. Kim, "Synthesis of gold-spikes decorated biomimetic silica microrod for photothermal agents," Journal of Industrial and Engineering Chemistry, vol. 58, pp. 33-37, 2018.

[22] Y. Ling, X. Zeng, W. Tan, J. Luo, and S. Liu, "Quaternized chitosan/rectorite/AgNP nanocomposite catalyst for reduction of 4-nitrophenol," Journal of Alloys and Compounds, vol. 647, pp. 463-470, 2015.

[23] C. Wang, X. Gao, Z. Chen, Y. Chen, and H. Chen, "Preparation, characterization and application of polysaccharidebased metallic nanoparticles: a review," Polymers, vol. 9, p. 689, 2017.

[24] Y. Hu, L. He, J. Ding, D. Sun, L. Chen, and X. Chen, “One-pot synthesis of dextran decorated reduced graphene oxide nanoparticles for targeted photo-chemotherapy," Carbohydrate Polymers, vol. 144, pp. 223-229, 2016.

[25] D. Medhat, J. Hussein, M. E. El-Naggar et al., "Effect of audextran NPs as anti-tumor agent against EAC and solid tumor in mice by biochemical evaluations and histopathological investigations," Biomedicine \& Pharmacotherapy, vol. 91, pp. 1006-1016, 2017.

[26] M. A. Hussain, A. Shah, I. Jantan et al., "One pot light assisted green synthesis, storage and antimicrobial activity of dextran stabilized silver nanoparticles," Journal of Nanobiotechnology, vol. 12, pp. 1-6, 2014.

[27] M. S. Dar, S. A. Ganaie, W. Raja, and R. A. Teeli, "In-vivo investigation on antifungal properties of leaf extracts of certain medicinal plants through seed treatment and foliar sprays against rice blast disease (Magnaporthe grisea) in Kashmir, India," Annals of Agrarian Science, vol. 16, no. 3, pp. 267271, 2018.

[28] Y. Ke, M. Wu, Q. Zhang, X. Li, J. Xiao, and S. Wang, "Hd3a and OsFD1 negatively regulate rice resistance to Xanthomonas oryzae pv. Oryzae and Xanthomonas oryzae pv. Oryzicola,"
Biochemical and Biophysical Research Communications, vol. 513, no. 4, pp. 775-780, 2019.

[29] Y. K. Jo, B. H. Kim, and G. Jung, "Antifungal activity of silver ions and nanoparticles on phytopathogenic fungi," Plant Disease, vol. 93, no. 10, pp. 1037-1043, 2009.

[30] M. Mankad, G. Patil, D. Patel, P. Patel, and A. Patel, "Comparative studies of sunlight mediated green synthesis of silver nanoparaticles from Azadirachta indica leaf extract and its antibacterial effect on Xanthomonas oryzae pv. oryzae," Arabian Journal of Chemistry, vol. 13, pp. 2865-2872, 2020.

[31] Y. Liang, D. Yang, and J. Cui, "A graphene oxide/silver nanoparticle composite as a novel agricultural antibacterial agent against Xanthomonas oryzae pv. Oryzae for crop disease management," New Journal of Chemistry, vol. 41, no. 22, pp. 13692-13699, 2017.

[32] T. D. Majumdar, M. Singh, M. Thapa, M. Dutta, A. Mukherjee, and C. K. Ghosh, "Size-dependent antibacterial activity of copper nanoparticles against Xanthomonas oryzae pv. oryzae - a synthetic and mechanistic approach," Colloid and Interface Science Communications, vol. 32, article 100190, 2019.

[33] J. Cui, Y. Liang, D. Yang, and Y. Liu, "Facile fabrication of rice husk based silicon dioxide nanospheres loaded with silver nanoparticles as a rice antibacterial agent," Scientific Reports, vol. 6, pp. 1-10, 2016.

[34] Y. Abdallah, S. O. Ogunyemi, A. Abdelazez et al., "The green synthesis of $\mathrm{MgO}$ nano-flowers UsingRosmarinus officinalisL. (Rosemary) and the antibacterial activities againstXanthomonas oryzaepv.oryzae," BioMed Research International, vol. 2019, Article ID 5620989, 8 pages, 2019.

[35] J. M. Vincent, "Distortion of fungal hyphæ in the presence of certain inhibitors," Nature, vol. 159, p. 850, 1947.

[36] S. S. John Xavier, C. Karthikeyan, G. Gnana Kumar, A. R. Kim, and D. J. Yoo, "Colorimetric detection of melamine using $\beta$ cyclodextrin-functionalized silver nanoparticles," Analytical Methods, vol. 6, no. 20, pp. 8165-8172, 2014.

[37] L. Thi, T. Thai, N. Duc, D. Quang, and D. Tuan, "Shape and size controlled synthesis of au nanorods: $\mathrm{H}_{2} \mathrm{~S}$ gas-sensing characterizations and antibacterial application," Journal of Alloys and Compounds, vol. 635, pp. 265-271, 2015.

[38] S. Devarajan, P. Bera, and S. Sampath, "Bimetallic nanoparticles: a single step synthesis, stabilization, and characterization of au-Ag, au-Pd, and au-Pt in sol-gel derived silicates," Journal of Colloid and Interface Science, vol. 290, no. 1, pp. 117129, 2005.

[39] J. Yang, J. Y. Lee, and H. Too, “Core-shell Ag-au nanoparticles from replacement reaction in organic medium," The Journal of Physical Chemistry. B, vol. 109, no. 41, pp. 19208-19212, 2005.

[40] S. Pramanik, S. Chattopadhyay, and K. Das, "Extremely fast au-Ag alloy-dealloy associated reversible plasmonic modifications in SiO2films," Journal of Materials Chemistry C, vol. 4, no. 16, pp. 3571-3580, 2016.

[41] H. Alishah, S. Pourseyedi, S. E. Mahani, and S. Y. Ebrahimipour, "Extract-mediated synthesis of Ag@AgCl nanoparticles using: Conium maculatum seeds: characterization, antibacterial activity and cytotoxicity effect against MCF-7 cell line," RSC Advances, vol. 6, no. 77, pp. 73197-73202, 2016.

[42] E. E. Elemike, D. C. Onwudiwe, N. Nundkumar, M. Singh, and O. Iyekowa, "Green synthesis of Ag, au and Ag-au bimetallic nanoparticles using Stigmaphyllon ovatum leaf extract and their in vitro anticancer potential," Materials Letters, vol. 243, pp. 148-152, 2019. 
[43] K. Gopinath, S. Kumaraguru, K. Bhakyaraj et al., "Green synthesis of silver, gold and silver/gold bimetallic nanoparticles using the Gloriosa superba leaf extract and their antibacterial and antibiofilm activities," Microbial Pathogenesis, vol. 101, pp. 1-11, 2016.

[44] Y. Yin, Z. Y. Li, Z. Zhong, B. Gates, Y. Xia, and S. Venkateswaran, "Synthesis and characterization of stable aqueous dispersions of silver nanoparticles through the Tollens process," Journal of Materials Chemistry, vol. 12, no. 3, pp. 522-527, 2002.

[45] R. Z. Ahmed, K. Siddiqui, M. Arman, and N. Ahmed, "Characterization of high molecular weight dextran produced by Weissella cibaria CMGDEX3," Carbohydrate Polymers, vol. 90, no. 1, pp. 441-446, 2012.

[46] R. K. Purama, P. Goswami, A. T. Khan, and A. Goyal, "Structural analysis and properties of dextran produced by Leuconostoc mesenteroides NRRL B-640," Carbohydrate Polymers, vol. 76, no. 1, pp. 30-35, 2009.

[47] B. Kumar, K. Smita, L. Cumbal, and A. Debut, "Green synthesis of silver nanoparticles using Andean blackberry fruit extract," Saudi Journal of Biological Sciences, vol. 24, no. 1, pp. 45-50, 2017.

[48] K. Sapkota and S. S. Han, "A Novel environmentally sustainable synthesis of au-Ag@AgCl nanocomposites and their application as an efficient and recyclable catalyst for quinoline synthesis," New Journal of Chemistry, vol. 41, no. 13, pp. 53955402, 2017.

[49] L. Liu, J. Liu, Y. Wang, X. Yan, and D. D. Sun, "Facile synthesis of monodispersed silver nanoparticles on graphene oxide sheets with enhanced antibacterial activity," New Journal of Chemistry, vol. 35, no. 7, pp. 1418-1423, 2011.

[50] C. C. P. Megan, S. Holden, J. Black et al., “Antibacterial activity of partially oxidized $\mathrm{Ag} / \mathrm{Au}$ nanoparticles against the oral PathogenPorphyromonas gingivalisW83," Journal of Nanomaterials, vol. 2016, Article ID 9605906, 11 pages, 2016.

[51] C. G. Tuchilus, M. Nichifor, G. Mocanu, and M. C. Stanciu, "Antimicrobial activity of chemically modified dextran derivatives," Carbohydrate Polymers, vol. 161, pp. 181-186, 2017. 